\title{
As implicações das Resoluções 1970 e 1973 do Conselho de Segurança da ONU pelos Direitos Humanos*
}

Johannes van Aggelen ${ }^{1}$

\section{Resumo}

O artigo demonstra o poder legislativo crescente do Conselho de Segurança da ONU nas últimas duas décadas, embora a doutrina não seja unânime.O Conselho nas resoluções 1970 e 1973 tomou medidas novas, não vistas nas resoluções anteriores. A Líbia passou recentemente perante o Conselho dos Direitos Humanos e o relatório, muito bom aos olhos do governo, foi bem criticado. Os eventos desde fevereiro e a resposta do governo nega todo conteúdo do relatório. A Líbia cometeu violações flagrantes dos direitos humanos. O Conselho dos Direitos Humanos estabeleceu um grupo de peritos, que publicou no início de junho um relatório detalhado, testemunhando graves violações de direitos humanos.

Palavras-chave: Conselho de Segurança. Poder legislativo. Conselho dos Direitos Humanos. Revisão universal. Grupo de peritos.

\section{Introdução}

As revoltas populares recentes no Oriente Médio clamando por reformas democráticas profundas despertou grande preocupação por parte da Comunidade Internacional, pela possível violação dos Direitos Humanos em países autocráticos daquela região. O Conselho de Segurança da ONU tomou medidas consideradas sem precedentes, levando em consideração a unanimidade de seus membros,

* Recebido em: 14.06.11. Aprovado em 29.08.11

1 Docteur en Droit, Holanda, 1976. Doctor Civil Law, Canadá, 1989. O autor agradece com muito carinho o auxílio prestado pelo colega e professor Henrique Pessoa na edição e inspiração intelectual do presente artigo. E-mail: hvanaggelen@hotmail.com. 
quando da votação das Resoluções 1970 e $1973^{2}$, aplicando sanções ao governo líbio, entre outros agravamentos.

Para poder avaliar as implicações sobre os Direitos Humanos, temos que discutir, brevemente, os poderes e prerrogativas presumíveis de caráter legislativos do próprio Conselho de Segurança.

\section{As resoluções tradicionais}

Historicamente, o Conselho de Segurança, baseado no artigo 39 da Carta das Nações Unidas ${ }^{3}$, é encarregado de resolver situações concretas e determinadas que ameacem a paz e a segurança internacional. O Conselho age com poder coercitivo sobre as nações-membro. No entanto, esses poderes somente podem ser exercidos em contexto limitado, para uma situação concreta e temporária, enquanto perdurar o estado de ameaça em questão. Outra questão é uma interpretação do artigo 25, que dispõe: “[...] os membros das Nações Unidas concordam em aceitar e executar as decisões do Conselho de Segurança de acordo com a presente Carta”.

A doutrina já levantou a possibilidade de que o Conselho poderia emitir resoluções obrigatórias que não envolvam a aplicação do capítulo VII. Uma análise extensiva desse artigo baseia-se no famoso Parecer Consultivo, proferido em 21 de junho de 1971 e intitulado "Consequências Jurídicas para os Estados da Presença Contínua da África do Sul na Namíbia (Sudoeste Africano) não obstante a Resolução 276 (1970) do Conselho de Segurança”. A Corte afirmou que uma interpretação que restrinja o campo de aplicação do artigo 25 privaria de sentido os

2 Resolução 1970 "Paz y Seguridad en Africa” e Resolução 1973 "La Situación en Libia”, Conselho de Segurança, resoluções de 2011.

3 CAPÍTULO VII: ARTIGO 39 - O Conselho de Segurança determinará a existência de qualquer ameaça à paz, ruptura da paz ou ato de agressão e fará recomendações ou decidirá que medidas deverão ser tomadas, de acordo com os Artigos 41 e 42, a fim de manter ou restabelecer a paz e a segurança internacional. 
artigos 48 e 49 da mesma ${ }^{4}$. Já em janeiro de 1956, um relatório da Comissão de Direito Internacional sobre a responsabilidade dos Estados observara a necessidade de adaptar o direito tradicional para que se refletisse uma transformação profunda que ocorrera no Direito Internacional ${ }^{5}$.

Mesmo assim, essa interpretação da Corte não era unânime, pois vários juízes se opuseram a essa visão ${ }^{6}$. Parece que o valor exato de cada Resolução, ou seja, se seu objetivo é de obrigar ou recomendar, deve ser deduzido da análise dos termos, como afirma a doutrina e o parecer supracitado (WOOD, 1998, p. 73-95; SIMMA, 2002, p. 453; CORTEN, 2002, p. 270; CIJ, 1970, p. 53).

Recapitulando, podemos constatar que o verdadeiro limite de poderes do Conselho se situa no plano de alcance de medidas que ele adota. Esse limite é duplo; por um lado só se pode tomar medidas particulares ligadas a uma situação determinada e não por uma via estritamente normativa. Por outro lado, o Conselho só pode adotar medidas provisórias que se atenham a condições em que se almeja mudar. Em suma, o Conselho de Segurança não pode modificar o Estado de Direito, realizar sua transformação permanente, mas, simplesmente, suspender ou modificar sua aplicação de maneira temporária (COMBACAU; SUR, 2004; MONTCHRESTEIN, 2004; DAILLIER; FORTEAU; PELLET, 2009).

${ }_{4}$ Corte Internacional de Justiça. Legal Consequences for States of the Continued Presence of South Africa in Namibia (South West Africa) notwithstanding Security Council Resolution 276 (1970), p.52,53 parágrafo.113. Disponível em: <http://www.icj-cij.org/docket/ index.php?p1=3\&p2=4\&code=nam \&case $=53 \& \mathrm{k}=\mathrm{a} 7>$. Acesso em: 10 jun. 2011.

5 Documento da ONU A/CN.4/SER.A/1956/Add.1.

6 Ver "DISSENTING OPINION OF JUDGE SIR GERALD FITZMAURICE”, p. 224-226, parágrafo.10, p. 293; parágrafos 113 e 114. Disponível em: <http://www.icj-cij.org/docket/ files/53/10789.pdf> supra note 4, p. 224-226, Disponível em: <http://www.icj-cij.org/docket/files/53/10789.pdf>. Acesso em 06 jun. 2011. Ver também "OPINION DISSIDENTE DE M. GROS” .p. 341,parágrafo.35. Disponível em: <http://www.icj-cij.org/docket/ files/53/10791.pdf>. Acesso em 06 jun. 2011 ; Ver também Dupuy (2008), p. 190-195. 


\section{As resoluções presumidas legislativas}

Em minha opinião, essa tendência nunca poderia ser efetivada sem a Queda do Muro de Berlim, ocorrida em novembro de 1989, que definitivamente mudou os parâmetros da comunidade internacional. O Direito Internacional Público, do modo que se desenvolveu durante o século XX, não aceitou que organizações intergovernamentais pudessem legislar Direito Internacional. O hard-law ou propriamente a lei vinculativa poderia ser somente criado por Estados mediante a adoção e ratificação dos tratados, a criação do direito consuetudinário por meio de prática geral e da opinio juris. As organizações intergovernamentais estariam aptas unicamente a fazer recomendações para seus Estados, e o Conselho de Segurança e a Assembleia Geral assim o fizeram durante meio século. Nas últimas duas décadas, o mesmo Conselho gradualmente adotou decisões não vinculadas a um conflito particular, e sim a conflitos gerais. Como exemplo, temos as resoluções destinadas à proteção das crianças, civis, questões humanitárias e ainda o terrorismo internacional ${ }^{7}$. Mesmo assim, essas resoluções foram articuladas em tom de insistência para com seus membros, na atuação em conformidade com a Carta das Nações Unidas.

Se essa atividade quase-legislativa do Conselho não suscitava muitas reações desfavoráveis devido à ausência de força obrigatória, a situação então mudou radicalmente em setembro de 2001, depois dos ataques terroristas aos EUA, quando o Conselho promulgou a Resolução 1373, relativa à "ameaça à paz e segurança internacional, causada por atos de terrorismo", atuando, sob o fundamento do capítulo VII da Carta. A Resolução possui caráter obrigatório, impondo a seus membros a adoção de certas medidas permanentes, para o combate e prevenção ao terrorismo. É assim que podemos dizer que grande parcela dessa Resolução estabelece novas regras vinculativas de Direito Internacional e lhe vale a qualificação de "legislador internacional".

Essa Resolução roga que todos os Estados tomem certas ações contra o financiamento de atividades terroristas e estabelece um comitê antiterrorismo. Todos os Estados têm de prestar contas acerca da implementação de medidas to-

\footnotetext{
7 E.g. CS Res. 1261, 1265, 1269, 1296 e 1325.
} 
madas em combate ao terrorismo a esse comitê. $\mathrm{O}$ cunho abstrato, impessoal e permanente dessa Resolução, somado à sua força obrigatória, faz dessa redação um verdadeiro tratado internacional - segundo alguns juristas - por conter disposições que estabelecem verdadeiras normas de Direito Internacional (CONDORELLI, 2001, p. 835; SAZS, 2002, p. 643).

\section{0 impacto das Resoluções 1970 e 1973 do Conselho de Segurança sobre os Direitos Humanos}

Após termos avaliado a força legislativa do Conselho de Segurança da ONU, devemos aplicar seu potencial sobre as referências de direitos humanos nestas resoluções.

\subsection{O Relatório da Líbia perante o Conselho dos Direitos Humanos}

Em 2006, a Comissão de Direitos Humanos foi substituída pelo Conselho de Direitos Humanos, composto de 47 membros $^{8}$. O novo sistema de avaliação do cumprimento das obrigações com os Direitos Humanos pelos Estados-membros chama-se Revisão Periódica Universal (UPR, em inglês), estabelecido pelo Conselho de Direitos Humanos em junho de 2007. Esse sistema consiste em um relatório nacional do país em questão, e uma compilação preparada pelo Alto Comissariado para os Direitos Humanos, em Genebra. Além disso, forma-se uma troika para preparar o debate sobre o cumprimento das obrigações de um dado país na esfera dos direitos humanos. Os 192 Países-membros da ONU assim são avaliados em um ciclo de quatro anos.

A Líbia surgiu perante o Conselho em novembro de 2010, e a troika foi constituída por Argentina, Noruega e Senegal ${ }^{9}$. A troika recebeu uma lista de perguntas dos seguintes países: Reino Unido, República Tcheca, Dinamarca, Alemanha, Letônia, Noruega, Eslovênia, Suécia e Países Baixos.

8 Res. da Assembleia Geral 61/251 de 15 de março de 2006.

9 Relatório do Grupo de Trabalho A/HRC/16/15, 04/01/2011. 
Do relatório, destacamos os seguintes pontos convenientes:

- A Líbia estava convencida de que a promoção e a proteção dos direitos humanos era um dos fatores mais importantes para o progresso e desenvolvimento dos povos. Em 1969, a primeira declaração da Grande Revolução incluiu um chamado em favor da igualdade e da não discriminação; em 1988, a Líbia publicou a Grande Carta Verde dos Direitos Humanos, estabelecendo que todos os seres humanos nasceram livres e iguais. A Líbia fazia parte da maioria dos tratados em direitos humanos e protocolos, e esses instrumentos têm precedência sobre as leis internas e poderiam ser aplicados diretamente nos tribunais domésticos (parágrafo 8 do Relatório);

- A Líbia garantia a proteção dos direitos humanos, não somente dos direitos políticos, como também os direitos econômicos, sociais e culturais (parágrafo 11 do Relatório);

- A Delegação afirmou que as mulheres são muito respeitadas e que seus direitos estão garantidos pela legislação (parágrafo 12);

- A imigração ilegal era um dos maiores problemas do país, tendo efeitos negativos no desenvolvimento, saúde e a estabilidade social em geral (parágrafo 13);

- A Líbia estava convencida de que a educação em direitos humanos era um dever do Estado, e das organizações civis competentes (parágrafo 14);

- A Líbia garantia a liberdade de expressão e religião, sendo que todo cidadão tem direito de expressar abertamente suas opiniões e ideias (parágrafos 16 e 17);

- A Líbia protege as pessoas contra a tortura e maus tratos (parágrafo 18); e

- 46 países participaram do diálogo interativo e fizeram 96 recomendações. 30 delas foram apoiadas pela Líbia. 
Destacam-se as principais recomendações:

- Adotar e aplicar uma definição da tortura conforme o Pacto Internacional de Direitos Civis e Políticos e a Convenção contra a Tortura;

- Aprovar uma legislação doméstica para abolir a prática da tortura;

- Continuar a promoção e a proteção dos direitos humanos e as liberdades fundamentais do povo líbio;

- Promover a educação em direitos humanos e ampliar a cultura dos direitos humanos;

- Tomar medidas destinadas a proteger mulheres e crianças contra a violência doméstica e adotar uma estratégia nacional nessa direção;

- Investigar denúncias de desaparecimentos forçados e aderir à Convenção Internacional de 2006;

- Investigar acusações de discriminação racial;

- Aprovar leis que ampliem a liberdade de expressão, associação e a revisão judicial;

- Garantir a independência do poder judiciário e respeitar as normas internacionais;

- Formular as declarações previstas no artigo 14 da CEDR (Convenção contra o Racismo) e artigo 22 da Convenção contra a Tortura, que possibilitam o locus standing do indivíduo perante os Comitês; e

- Abolir a pena de morte e estabelecer uma moratória sobre execuções (recomendação do Brasil, México, França e Austrália);

\subsection{As implicações das Resoluções do Conselho de Segurança pelos Direitos Humanos.}

Com a adoção da Resolução 1970, o Conselho preocupou-se com uma gama de violações de direitos humanos e de direito humanitário pelo governo líbio. Essa Resolução não somente foi adotada unanimemente, como também é uma das primeiras resoluções mais vinculadas pelos direitos humanos do que 
pela política. O Conselho de Segurança destacou os seguintes pontos na parte preâmbulo:

- Exprimir grave inquietação pela situação na Líbia, e condenar a violência e uso da força contra os civis;

- Reprovar a violação flagrante e sistemática dos direitos humanos, incluindo a repressão às manifestações pacíficas e também rejeitando incitamento à hostilidade e violência contra os civis, por parte do governo líbio;

- A recepção dos votos de condenação pela Liga Árabe, União Africana e a Organização da Conferência Islâmica, em favor das graves violações dos direitos e o direito humanitário pelo governo líbio;

- A validação da Resolução do Conselho dos Direitos Humanos A/ HRC/RES/S-15/1 de 25 de março de 2011, na qual o Conselho recomendou à Assembleia Geral excluir a Líbia e decidiu enviar uma comissão independente para investigar todas as alegações de violações dos diretos humanos e identificar os responsáveis ${ }^{10}$;

- Os ataques sistemáticos poderiam resultar em crimes de guerra;

- Inquietação sobre a má condição dos refugiados forçados a escaparem da violência e da falta de remédios; e

- A responsabilidade do governo em proteger a população;

Nesse contexto, podemos observar que o direito de intervenção humanitária era um dos pontos mais controversos na política internacional (RICOBOM, 2010). Ressalte-se a situação em Kosovo e a polêmica sobre a Resolução do Conselho 1244, de 10 de junho de 1999. Além disso, a situação em Ruanda, onde não houve êxito na intervenção humanitária, desencadeando uma Guerra Civil, em 1993-1994. O então secretário-geral da ONU, Kofi Annan, propôs à comunidade internacional o estabelecimento de regras sobre quando a intervenção deveria ocorrer, quem a chefiaria e como funcionaria. O governo canadense organizou uma comissão

\footnotetext{
${ }^{10}$ A Assembleia Geral excluiu a Líbia em 1 de março de 2011, doc. A/RES/65/265.
} 
internacional sobre a intervenção e soberania estatal em setembro de 2000, visando elucidar essa questão. Em 2002, a comissão lançou o relatório chamado "A Responsabilidade de Proteger ${ }^{11}$ ".

- A referência ao artigo 16 do Estatuto do Tribunal Penal Internacional possibilitando uma investigação 12 meses depois do pedido do Conselho de Segurança;

- Inquietação sobre a segurança dos cidadãos estrangeiros e seus direitos;

- A responsabilidade primária ressalta a manutenção da paz e segurança; e

- As medidas tomadas submetem-se ao Capitulo VII, artigo 41 da Carta;

Na parte operativa, o Conselho de Segurança destacou os seguintes pontos:

- Insistência no cumprimento das reclamações legítimas do povo líbio;

- Impulsionar as autoridades da Líbia a agirem com a máxima cautela, respeitarem os direitos humanos e o direito internacional humanitário e autorizarem monitores de direitos humanos;

- Garantir a segurança dos estrangeiros desejosos em sair do país e roga a todos os membros da ONU pela cooperação;

- Assegurar o trabalho das agências humanitárias e o provimento dos remédios ;

- Encaminhar a situação da Líbia ao promotor público do TPI e determinar que as autoridades tenham a obrigação de cooperar;

- Solicitar a todos os Estados para que cooperem com a Corte;

- Pedir a todos os Estados para que respeitem o embargo de armas conforme artigo 41 da Carta;

- Empossar-se e confiscar todo o material encontrado em violação e encaminhar um relatório ao Comitê estabelecido conforme parágrafo 24 desta Resolução;

${ }^{11} \mathrm{O}$ relatório está disponível no seguinte sítio: http://www.iciss.ca/menu-en.asp. Acesso em 11.06.11. 
- Impedir viagens à Líbia que possam contribuir com a violação dos direitos humanos;

- Impedir a viagem de pessoas mencionadas no Anexo I e congelamento de bens das pessoas no Anexo II; e

- Pedir com insistência a todos os Estados que facilitem a assistência humanitária;

A Resolução 1973 adotada em 17 de março de 2011 reafirma quase todos os destaques da Resolução 1970, com algumas diferenças:

- O Conselho condenou atos de violência e intimidação contra os jornalistas e profissionais em medicina, e solicitou às autoridades líbias o cumprimento de suas obrigações para com os ditames do direito internacional humanitário, como delineado pela Resolução 1736, de 23 de dezembro de 2006, intitulado como “A Proteção dos Civis em Conflitos Armados";

- Desaprovação do uso contínuo de mercenários e solicitação para que todos os estados cumpram com suas obrigações, conforme o parágrafo $9^{\circ}$ da resolução 1970 ;

- Exige, mais uma vez, que as autoridades cumpram suas obrigações, em conformidade com o direito internacional, direito internacional humanitário, como os direitos humanos e o direito dos refugiados, para que todos os civis sejam protegidos e lhes seja fornecida assistência humanitária;

- Estabelecer uma zona de exclusão aérea para melhor proteção da população civil; e

- Requerer ao Secretário Geral da ONU o estabelecimento de um painel de oito peritos para que assistam o Comitê referido no parágrafo $24^{\circ}$ da Resolução 1970 ; 


\subsection{Relatório da Comissão Internacional de inquérito para investigar todas as presumidas violações de direitos humanos na líbia ${ }^{12}$}

Esta Comissão foi estabelecida de acordo com o parágrafo 11 da Resolução S-15/1 do Conselho de Direitos Humanos, em 25 de fevereiro de 2011.

A Comissão decidiu considerar ações de todas as partes envolvidas no conflito, optando por investigar violações dos direitos humanos, como também do direito humanitário, baseado no princípio lex speciales derogat lex generales ${ }^{13}$. Em particular, a Comissão considerou que, entre 15 a 24 de fevereiro de 2011, as demonstrações e a reação governamental realizaram-se em tempos de paz, necessitando da análise nos parâmetros dos direitos humanos. Depois do dia 24 de fevereiro, deflagrou-se um conflito armado não internacional. Quando o Conselho de Segurança executou a Resolução 1973, passou a coexistir um conflito armado internacional. Nesse caso, as normas do direito internacional humanitário relativas a conflitos armados internacionais eram aplicáveis.

A comissão destacou as seguintes violações graves no que concerne aos direitos humanos e humanitários:

- A força desproporcional contra manifestantes, resultando em mortos e feridos, infringindo o direito à vida, à incolumidade das pessoas, liberdade de reunião e expressão;

- As forças pró-governo detiveram arbitrariamente muitas pessoas, em contrariedade ao Pacto Internacional sobre Direitos Civis e Políticos, em seu artigo 9;

- O governo da Líbia promoveu o desaparecimento de manifestantes anti-Gaddafi, infringindo mais uma vez os acordos sobre direitos humanitários e humanos;

\footnotetext{
${ }^{12}$ Doc A/HRC/17/44 de1 de junho de 2011.

${ }^{13}$ Vide "Legal Consequences of the Construction of a Wall in the Occupied Palestinian Territory”, Advisory Opinion, I.C.J. Reports 2003, p. 178, parágrafo 106. Disponível em: http://www.icj-cij.org/docket/index.php?p1=3\&p2=4\&code $=$ mwp\&case $=131 \& \mathrm{k}=5 \mathrm{a}$. Acesso em 09.06.11
} 
- A prática de tortura e outras formas de tratamento cruel, desumano e degradante, foram cometidas por ambos os lados;

- O acesso a tratamento médico foi impedido pelo governo, o que demonstra uma violação grave da garantia de acesso à saúde;

- O governo líbio cometeu graves ataques a jornalistas, impedindoos de divulgar suas matérias para o exterior;

- As forças governamentais cometeram ataques indiscriminados contra civis, além de abusar dos distintivos das Convenções de Genebra durante o conflito;

- A Comissão conclui que estrangeiros foram contratados como mercenários pelo governo de Gaddafi;

- Trabalhadores imigrantes subsaarianos foram maltratados durante os conflitos, por terem sido considerados mercenários pelos manifestantes anti-Gaddafi;

- A falta de legitimidade nas autoridades líbias para proteger essa categoria de trabalhadores se dirige à responsabilidade de Estado;

- A Comissão não pôde verificar precisamente os casos de estupro e também o aliciamento de menores para o conflito armado;

- A comissão concluiu que muitas violações cometidas poderiam ser qualificadas como crimes de guerra, de acordo com o estatuto do TPI. Também foi valorado que as forças do governo cometeram mais crimes internacionais que seus opositores; e

- A Comissão determinou que não poderia identificar os responsáveis pelas infrações, como requerido pela Comissão de Direitos Humanos.

\subsection{Recomendações}

A Comissão emitiu as seguintes recomendações ao governo líbio:

- Cessar imediatamente todos os atos de violência contra os civis;

- Investigar paulatinamente todas as violações presumidas do direito internacional dos direitos humanos e direito internacional humanitário, e, particularmente, combater execuções extralegais 
e arbitrárias, desaparecimentos e tortura, respeitando todas as garantias e procedimentos judiciais;

- Absolver incondicionalmente todos os indivíduos que participaram de manifestações pacíficas e revelar o nome dos civis mantidos sob custódia;

- Viabilizar reparações por quaisquer danos, de modo adequado, às vítimas e a seus familiares;

- Assegurar acesso irrestrito aos locais de detenção a todas as organizações humanitárias e de direitos humanos, para que realizem entrevistas aos detentos, sem constrangimento ilegal; e

- Garantir que todas as leis da Líbia estejam em conformidade com o direito internacional de direitos humanos.

Além das recomendações supracitadas, a Comissão exige do Conselho Transnacional:

- Controle severo dos armamentos sob posse dos civis; e

- Respeito e facilitação do acesso aos necessitados e enfermos pelos órgãos humanitários.

A Comissão considerou que a situação calamitosa e complexa requer mais tempo de análise e recomendou ao Conselho de Direitos Humanos o prolongamento da mesma comissão por mais um ano.

\section{Considerações finais}

O relatório detalhado da Comissão demonstra claramente a não observação das regras de base do direito internacional humanitário e dos direitos humanos por ambas as partes. As demonstrações de crueldade e arbitrariedade do governo líbio ante seus próprios cidadãos põem em descrédito os termos apresentados no relatório ao Conselho de Direitos Humanos. O conflito converge as obrigações desses direitos e do direito penal internacional. O promotor do TPI já forneceu seu relatório inicial em face do pedido do Conselho de Segurança, e, seguramente, irá produzir materiais subsequentes a ela. 
O problema principal, a saber, é se as Resoluções 1970 e 1973, e também as resoluções do Conselho de Segurança em geral exigem de todos os Estados-membro da Carta o cumprimento de todas as suas exigências. A equivalência de poder do Conselho a um poder legislativo não é definitiva; O direito internacional se desenvolve e as providências da Carta no século XXI não podem ser interpretadas ipsis literis. As muitas comissões estabelecidas direta ou indiretamente pelo Conselho de Segurança, nas últimas décadas, dão ímpeto a considerar que o Conselho tem na ordem mundial de nosso tempo influência considerável sobre as questões do direito internacional humanitário, dos direitos humanos e do direito penal internacional.

\section{Implications of United Nations Security Council Resolutions 1970 and 1973 on Human Rights}

\section{Abstract}

The article shows the increasing legislative power of the UN Security Council over the last two decades, although the doctrine is not unanimous on the issue. The Council,in itstwo resolutions (1970 and 1973) took new measures,not seen in previous resolutions. Libya appeared recently before the Human Rights Council and the report,very good in the eyes of the government,was seriously critized.The events as of february and the government's reaction defies the content of the report. Libya committed flagrant violations of human rights. The Human Rights Council established a group of experts, which in early June published a detailed report which testified to grave violations.

Keywords: Security Council. Legislative power. Human Rights Council. Universal periodic Review. Group of experts. 


\section{Referências}

DAILLIER, P. ; FORTEAU, M. ; PELLET, A. Droit international public, Bruxelas: Ed. Bruylant, 2009.

COMBACAU, J; SUR, S. Droit international publique. $6^{\text {th }}$ ed. Paris, 2004.

CONDORELLI, L. Les attentats du 11 septembre et leurs suítes: où vale droit international? Revue General de Droit International publique, Paris, v. 4, p. 829-848, 2001.

CORTE INTERNACIONAL DE JUSTIÇA. Legal Consequences for States of the Continued Presence of South Africa in Namibia (South West Africa) notwithstanding Security Council Resolution 276 (1970). Disponível em: <http://www.icj-cij.org/docket/index. php?p1=3\&p2=4\&code=nam \&case=53\&k=a7> . Acesso em: 29 ago. 2011.

. Legal Consequences of the Construction of a Wall in the Occupied Palestinian

Territory, Advisory Opinion, I.C.J. Reports 2003. Disponível em: <http://www.icjcij.org/docket $/$ index.php?p1 $=3 \& \mathrm{p} 2=4 \& \operatorname{code}=$ mwp $\&$ case $=131 \& \mathrm{k}=5 \mathrm{a}>$. Acesso em 09 jun. 11

CORTEN, O. Vers un reforcement des pouvoirs du Conseil de Sécurité dans la Lute contre le Terrorisme? In: K. Bannelier ,T. Christakis, O. Corten, B. Delcourt. Le droit internationale face au terrorisme. Paris: Pedone, 2002.

COT, Jean-Pierre et al. La charte des Nations Unies: commentaire article par article. 3. ed. Paris, 2005.

DUPUY, Pierre Marie. Droit international publique. Paris: Dalloz, 2008.

MONTCHRESTEIN; DENNIS, C. Le pouvoir normatif du Conseil de Sécurité des Nations Unies: portée et limites. Bruxelas: Bruylant, 2004.

RICOBOM, Gisele. Intervenção humanitária: a guerra em nome dos direitos humanos. Belo Horizonte: Fórum, 2010.

SIMMA, B. The charter of the United Nations: a commentary. $2^{\text {th }}$ ed. Oxford: Oxford University, 2002.

SZASZ, P. The Security Council Starts Legislating. American Journal of International Law, Washington, v. 96, n. 4, p. 901-905, out. 2002.

WOOD, M. The interpretation of Security Council Resolutions. [S.l.]: Max Planck Yearbook of United Nations, 1998. v. 2. 


\section{Para publicar na revista Universitas}

Relações Internacionais, entre no endereço eletrônico www.publicacoesacademicas.uniceub.br. Observe as normas de publicação, facilitando e agilizando o trabalho de edição. 